ARTIGO

\title{
Políticas públicas na alfabetização: um diálogo com a avaliação nacional da alfabetização e o Programa Mais Alfabetização*
}

Helen Vieira de Oliveira ${ }^{a}$ Dina Maria Vieira Pinho ${ }^{b}$ Luiz Antônio Gomes Senna ${ }^{c}$

\section{Resumo}

O histórico resultado de fracasso na alfabetização no contexto brasileiro e as políticas públicas desenvolvidas a partir desse cenário são objetos de discussão desse texto, que explora a relação entre a avaliação externa da aprendizagem do aluno, as políticas públicas e o cotidiano das práticas pedagógicas. Para tanto, optou-se por realizar uma análise do documento norteador do Programa Mais Alfabetização, implementado em 2018, em resposta aos baixos níveis de desempenho dos alunos na Avaliação Nacional de Alfabetização. Com base em contribuições da literatura, é apresentada uma discussão teórica sobre as políticas públicas de alfabetização e a avaliação externa da aprendizagem do aluno. $\mathrm{O}$ que observamos é que, em síntese, o programa desenvolvido em resposta aos resultados da avaliação externa tende a focar na formação e na atuação docente, no controle e no monitoramento das práticas pedagógicas.

Palavras-chave: Alfabetização. Avaliação Externa. Políticas Públicas.

\section{Introdução}

Esse estudo pretende discutir os resultados da Avaliação Nacional de Alfabetização (ANA) (BRASIL, 2013) e a repercussão no campo das políticas públicas e no cotidiano das práticas pedagógicas do professor. Ele foi realizado a partir da

\footnotetext{
* Financiamentos: Fundação de Amparo à pesquisa do Estado do Rio de Janeiro - Faperj PQ/ CNE\#E26-202926/2017; Universidade do Estado do Rio de Janeiro - Uerj PQ/Prociencia (2020-2023).

a Universidade de Lisboa, Lisboa, Portugal.

b Universidade do Estado do Rio de Janeiro, Rio de Janeiro, RJ, Brasil.

c Universidade do Estado do Rio de Janeiro, Rio de Janeiro, RJ, Brasil.
} 
análise dos dados dessa avaliação externa e do Programa Mais Alfabetização, lançado em 2018, com o objetivo de fortalecer e de apoiar as unidades escolares no processo de alfabetização. Esse texto, além da introdução e da conclusão, apresenta três seções: diálogo entre os campos de políticas públicas e alfabetização; apresentações de avaliações em larga escala na alfabetização; e uma análise de políticas públicas e resultados da ANA.

\section{Políticas públicas em alfabetização}

A construção de uma escola democrática brasileira, passado mais de um século, ainda não se concretizou. A história da alfabetização brasileira, principalmente a que se deu nas escolas da rede pública, se confunde com a história do fracasso escolar. Em sua pesquisa de doutoramento, Spala (2015) nos apresenta uma radiografa da alfabetização carioca. Nela, a autora revela que, apesar de todos os projetos de correção de fluxo, a Educação Pública do município do Rio de Janeiro ainda não alfabetiza um número significativo de alunos.

Na busca por uma solução definitiva, métodos foram criados e, a cada momento, origina-se uma nova abordagem. Da síntese à análise, da letra ao texto, houve muitos pontos de partida, mas nenhum método conseguiu levar todos os alunos ao ponto de chegada, deixando, por conseguinte, algum educando pelo caminho. Alguns desses recomeçaram, porém, muitos desistiram ou foram levados a desistir.

Para Mortatti (2010, p. 329), a alfabetização na língua materna é "um processo complexo e multifacetado que envolve ações especificamente humanas e, portanto, políticas, caracterizando-se como dever do Estado e direito constitucional do cidadão". Porém, apesar dessas características, as políticas públicas nessa área nem sempre consideraram esse fato. Como afirma Mortatti (2010, p. 329), detiveram-se nas políticas públicas um ou em alguns aspectos específicos da alfabetização, o que vem a "reduzir esse processo a aspectos neutros e meramente técnicos".

Ao longo da história, o Brasil passou por alguns marcos com relação às políticas públicas voltadas para a alfabetização. O primeiro, que remete aos anos de 1930, é o entendimento de que o melhor índice de qualidade da escola pública, laica e gratuita era o saber ler e escrever. Para atender a essa demanda, vários métodos são criados, acabando por acarretar uma disputa de métodos. É importante destacar esse ponto, tendo em vista que "decisões políticas estão na base de políticas públicas como manifestações sintéticas das relações entre teoria e ação do Estado" (MORTATTI, 2010, p. 331). 
No início da década de 1980, há um olhar maior para o período de alfabetização, visto que nessa etapa concentrava-se a maior parte da população das classes menos favorecidas e que vinha fracassando na escola pública. Com isso, buscou-se focar nas ações públicas para melhorar a Educação nessa etapa. Nesse período, oficializou-se, no âmbito de políticas públicas para alfabetização, o modelo teórico com base no construtivismo, o que acarretou uma desmetodização da alfabetização. Outras duas teorias também configuraram o campo teórico da alfabetização nessa época, a saber: interacionismo linguístico e letramento, como propostas didático-pedagógicas. Sobre essa passagem de diferentes métodos para um momento de desmetodização, Mortatti (2010) afirma:

Trato aqui, porém, de modelos relativamente objetivos e definidos apenas no nível teórico, pois, no nível das apropriações e concretizações didático-pedagógicas e mesmo em inúmeras pesquisas acadêmicas, assim como no âmbito de documentos que condensam políticas públicas, dificilmente se constatam ocorrências e aplicações puras de um ou outro modelo; além do construtivismo e do interacionismo linguístico, pode-se ainda observar, nas práticas alfabetizadoras, atividades didáticas baseadas nos antigos métodos de alfabetização - sintéticos, analíticos e mistos - utilizados no Brasil desde o século XIX (p. 333).

Em 2001, foi lançado o primeiro Plano Nacional Decenal de Educação, doravante PNE, com força de lei. O PNE 2001-2010 revelou o cenário da Educação brasileira e propôs objetivos e metas para todas as modalidades de Ensino. O segundo PNE, 2011-2020, propunha 20 metas. Em documento publicado pelo Ministério da Educação (MEC), está posto que

a fim de que o PNE não redunde em uma carta de boas intenções incapaz de manter a mobilização social pela melhoria da qualidade da Educação, é preciso associar a cada uma das metas uma série de estratégias a serem implementadas pela União, pelos Estados e pelos Municípios em regime de colaboração (BRASIL, 2010).

No escopo desse trabalho, nos importa a meta 5: "alfabetizar todas as crianças até oito anos de idade". Na avaliação técnica dessa meta, declara-se que, apesar do processo de alfabetização e de letramento serem processos longos, é possível que, após cinco anos de escolarização formal, as crianças, aos oito anos, teriam atingido "um domínio satisfatório do sistema ortográfico" e desenvolvido "habilidades de escrita como, por exemplo, escrever um bilhete ou anotar um recado". Os cinco 
anos de escolarização a que se refere o texto incluem, além dos três primeiros anos do Ensino Fundamental, dois anos na Educação Infantil. Para que essa meta seja atingida, foram elencadas cinco estratégias, dentre as quais, a criação de um instrumento de avaliação periódica para aferir a alfabetização das crianças e estimular que os demais níveis de governo construam meios para monitorar e avaliar as medidas pedagógicas para a alfabetização de todos os estudantes ao final do $3^{\circ}$ ano do Ensino Fundamental.

No ano de 2012, o então ministro da Educação instituiu o Pacto Nacional pela Alfabetização na Idade Certa (Pnaic). Essa ação do Ministério da Educação, com a participação dos governos federal, estaduais e municipais, tinha o objetivo de combater os altos índices de analfabetismo entre as crianças brasileiras em idade escolar. O Pnaic está organizado em quatro eixos: formação continuada presencial para professores alfabetizadores e seus orientadores de estudo; materiais didáticos, obras literárias, obras de apoio pedagógico, jogos e tecnologias educacionais; avaliações sistemáticas; gestão, controle social e mobilização. Dentre esses, foi destacado como eixo principal "a formação continuada de professores alfabetizadores" (BRASIL, 2015, p. 10). De acordo com o documento, "trata-se, portanto de, em sentido amplo, apresentar encaminhamentos metodológicos que possibilitem o desenvolvimento dos Direitos de Aprendizagem dentro do ciclo de alfabetização" (BRASIL, 2015, p. 10). No que se refere às avaliações sistemáticas, o documento prevê a criação de um instrumento de avaliação para aferir os níveis de alfabetização dos alunos e alunas do $3^{\circ}$ ano do Ensino Fundamental.

Após uma revisão da literatura sobre o Pnaic, Alferes e Mainardes (2019) revelam que o contexto de sala de aula e a relação do pacto, enquanto política educacional, são pouco abordados, merecendo mais atenção. Shimazaki e Menegassi (2016) concluem que o programa possui limitações, no entanto, apresenta-se como possibilidade para a organização do trabalho pedagógico e de estudo e de pesquisa para os professores pesquisadores. Já Schneider et al. (2020), ao realizarem uma pesquisa relacionando o programa com a formação de professores, afirmam que, apesar de haver momentos de estudo teórico e prático na formação continuada em decorrência do programa, não houve comprovação de que ocorram mudanças conceituais significativas nas práticas docentes. Com uma pesquisa voltada para o material fornecido pelo Pnaic para o professor de Matemática, Ferreira e Fonseca (2017) evidenciam que os textos apresentados no caderno do programa são prescritivos, tendo em vista que direcionam para diretrizes do fazer e do agir docente. Dessa forma, desconsidera-se a capacidade e a formação do professor, ao que diminui seu trabalho intelectual e lhe confere uma função de mero executor de tarefas. Na mesma direção, segue a pesquisa desenvolvida por Esquinsani (2016), que assume que o Pacto considera a formação continuada como estratégia de 
repasse do accountability, sendo o professor coadjuvante no processo de formação e protagonista da responsabilização e da cobrança de resultados.

\section{Avaliação em larga escala na alfabetização}

Para se avaliar a qualidade da Educação, há tempos a necessidade de medir vem ganhando espaço. Em um $1^{\circ}$ momento, como afirma Casassus (2013), o foco deu-se nos fatores materiais que determinaram o resultado, ou seja, taxas de relação professor/aluno, número de livros em casa ou nas escolas, número de alunos por sala, dentre outros. Em seguida, passou-se a analisar hipóteses com fatores "imateriais", como as expectativas e as interações que se passavam na escola ou em casa. Por fim, no atual momento, a atenção está voltada para a observação e medição do sucesso acadêmico.

A avaliação externa da aprendizagem dos alunos propicia informação, diagnóstico, regulação, monitoramento e controle (do indivíduo e do sistema educacional) e legitimação das políticas (FERNANDES, 2008; KELLAGHAN; MADAUS, 2003). De acordo com Esteban (2012), a atual política de avaliação da alfabetização configura-se como uma ação altamente regulatória, haja vista que reduz a autonomia do professor, pelos mecanismos de controle ao qual se vincula, principalmente no que se refere ao planejamento cotidiano da prática pedagógica. A avaliação, segundo a autora, apresenta-se como meio de se alcançar qualidade na Educação, no entanto, possui fundamentos na redução de seu sentido e na simplificação das análises sobre a produção dos resultados escolares, vindo, por conseguinte, a diminuir as discussões em aspectos para além dos resultados da avaliação em larga escala. Em contrapartida, há aqueles que defendem a avaliação nesse ciclo, entendendo que é um instrumento que propicia um diagnóstico precoce da aprendizagem na alfabetização e um monitoramento das práticas de alfabetização, colaborando para a definição de políticas de formação continuada e de práticas de Ensino inclusivas (MORAIS et al., 2009).

Nos últimos anos, duas avaliações em larga escala fizeram parte do ciclo de alfabetização. A $1^{\text {a }}$ é a Provinha Brasil (BRASIL, 2008), uma avaliação diagnóstica do nível do desempenho do aluno, aplicada no $2^{\circ}$ ano do Ensino Fundamental, em dois momentos - no início e no final do mesmo ano letivo. A avaliação contempla provas de Língua Portuguesa (habilidade de leitura) e de Matemática, é aplicada anualmente e tem caráter opcional, pois fica a critério de cada Secretaria de Educação das unidades federadas. De acordo com o Instituto Nacional de Estudos e Pesquisas Educacionais Anísio Teixeira (Inep), a Provinha Brasil (BRASIL, 2008) tem como objetivos avaliar o nível de alfabetização dos educandos nos anos iniciais do Ensino Fundamental; fornecer respostas 
diretamente aos alfabetizadores e aos gestores escolares; e concorrer para a melhoria da qualidade de Ensino e redução das desigualdades (BRASIL, 2008). Outra avaliação da etapa de alfabetização, em que nos deteremos nas linhas que se seguem, é a Avaliação Nacional da Alfabetização (ANA) (BRASIL, 2013), que é censitária e aplicada a todos os alunos do $3^{\circ}$ ano do Ensino Fundamental da rede pública de Ensino.

\subsection{Avaliação Nacional da Alfabetização}

Em documento publicado em julho de 2013, é tornada pública uma proposta do Inep para a ANA. No artigo $9^{\circ}$, inciso IV da Portaria $n^{\circ} 867$, que instituiu o Pnaic (BRASIL, 2012), está prevista a realização de uma "avaliação externa universal do nível de alfabetização ao final do $3^{\circ}$ ano do Ensino Fundamental, aplicada pelo Inep". No art. $5^{\circ}$, inciso I, afirma-se que todas as ações sugeridas pelo Pacto têm como objetivo "garantir que todos os estudantes dos sistemas públicos de Ensino estejam alfabetizados, em Língua Portuguesa e em Matemática, até o final do $3^{\circ}$ ano do Ensino Fundamental" (BRASIL, 2013, p. 5). O documento esclarece que o foco direcionado ao Ciclo de Alfabetização é derivado da percepção de que é nessa fase da escolarização que deve ser garantido a cada uma das crianças, "o direito às aprendizagens básicas da apropriação da leitura e da escrita, e também à consolidação de saberes essenciais dessa apropriação, ao desenvolvimento das diversas expressões e ao aprendizado de outros saberes fundamentais das áreas e componentes curriculares obrigatórios" (BRASIL, 2013, p. 5).

O propósito dessa avaliação em ampla escala é fornecer indicadores que auxiliem no processo de alfabetização no âmbito das escolas públicas em todo território nacional. Para isso, além da aplicação de testes para medir o desempenho dos alunos, também é prevista a realização de uma análise das condições em que esse processo de escolarização acontece. Portanto, essa avaliação anual faz uso de diferentes instrumentos, cujos objetivos principais foram: "(i) avaliar o nível de alfabetização dos educandos no $3^{\circ}$ ano do Ensino Fundamental; (ii) produzir indicadores sobre as condições de oferta de Ensino e (iii) concorrer para a melhoria da qualidade do Ensino e redução das desigualdades" (BRASIL, 2013, p. 7).

De acordo com o artigo $1^{\circ}$, inciso I, da Portaria que institui o Pnaic, a avaliação em larga escala a ser realizada tem por objetivo diagnosticar a alfabetização e o letramento em Língua Portuguesa e em Matemática, ao final do Ciclo de Alfabetização. É explicado, no documento básico sobre a ANA, que o uso das palavras "alfabetização" e "letramento", na Portaria em questão, harmoniza-se com os debates que vêm acontecendo na academia nos últimos anos. A escolha desses termos expressa que, embora sejam dois processos distintos, eles se articulam e se complementam. Portanto, 
compreende-se que o Ciclo de Alfabetização deve proporcionar aos alunos mais do que a simples aquisição de um código, levando-os à construção dos significados e usos da língua escrita em diferentes contextos de comunicação. Dessa forma, alfabetização e letramento são conceitos fundamentais dessa avaliação ${ }^{1}$.

\section{Política pública a partir dos resultados da ANA e o impacto nas escolas}

O reiterado fracasso no desempenho dos alunos nas avaliações em larga escala nos faz pensar um pouco sobre sua proposta. O sistema de avaliação baseado em exames estandardizados vem ocupando lugar de destaque nas políticas oficiais, visando à melhoria da qualidade da Educação a partir da mensuração do desempenho dos estudantes, com base em uma busca de medida objetiva e estabelecimento de metas. Segundo Clímaco (2005, p. 55), frequentemente, essa forma de avaliação é "referida como um modo de fundamentar as políticas de reforma, e até certo ponto, é considerada como a expressão das preocupações com a qualidade e, genericamente, da democratização da Educação".

A partir dos anos de 1990, no que diz respeito ao Brasil, a discussão sobre avaliação externa da aprendizagem dos alunos começou a ser desenhada, devido à implantação do Sistema de Avaliação da Educação Básica (Saeb), tendo como objetivo o diagnóstico e a monitoração da qualidade da Educação. Em seguida, surge a Prova Brasil em 2005, que apresenta, juntamente com o Saeb, uma política de responsabilização branda (low stakes), que não tem consequências significativas, tangíveis ou diretas anexadas aos resultados, pois se entende que apenas a informação é suficiente como incentivo para as pessoas agirem. Nos anos de 2008 e de 2013, surgiram as avaliações do ciclo de alfabetização - respectivamente, Provinha Brasil (BRASIL, 2008) e ANA (BRASIL, 2013) -, também com responsabilização branda.

Entende-se que a ANA não apresenta periodicidade de aplicação consistente, no entanto, políticas públicas foram pensadas e divulgadas a partir dos dados apresentados por essa avaliação. A partir das duas edições da ANA de leitura, observa-se que há uma estagnação do desempenho dos alunos nas medições realizadas: mais de 50\% estão nos níveis 1 e 2, o que significa proficiência insuficiente. Na prova de escrita de $2016,34 \%$ dos alunos apresentaram proficiência insuficiente; $57 \%$, adequada e apenas $8 \%$, desejável. Após a divulgação do resultado, em outubro de 2017, da avaliação ocorrida em 2016, o Ministério da Educação apresentou o Programa Mais

Queremos ressaltar que a ANA também afere os níveis de alfabetização Matemática, porém, como foge ao escopo desse trabalho, não os abordaremos. 
Alfabetização (BRASIL, 2018), com o objetivo de reverter o quadro de estagnação na aprendizagem apresentado a partir do resultado da avaliação. O programa "visa fortalecer e apoiar as unidades escolares no processo de alfabetização dos estudantes regularmente matriculados no $1^{\circ}$ ano e no $2^{\circ}$ ano do Ensino Fundamental" (BRASIL, 2018), sendo de adesão voluntária, ou seja, o governador e o Secretário de Educação do estado seriam os responsáveis pela decisão de aderir ou não ao programa. No momento em que se optava pela participação, tornava-se obrigatória a realização da adesão ao Plano de Ações Articuladas do Sistema Integrado de Monitoramento e ao Controle do Ministério da Educação. Ao professor, também foi de caráter opcional aceitar o assistente de alfabetização em sala de aula.

A política foi fundamentada em um conjunto de iniciativas que envolvem a Base Nacional Comum Curricular, a formação de professores, o protagonismo das redes e o Programa Nacional do Livro Didático, como pode ser observado no Gráfico 1. Além dessas ações, o que mais se evidenciou foi a criação do Programa Mais Alfabetização (Portaria $n^{\circ}$ 142/2018), que trabalha a partir de uma tríade: gestão, formação e material.

O Gráfico 1 faz parte do documento "Política Nacional de Alfabetização" do Ministério da Educação (BRASIL, 2018), com o objetivo de apresentar o Programa Mais Alfabetização em outubro de 2017.

Gráfico 1 - Ações do Programa Mais Alfabetização

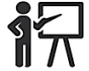

Apoio técnico e financeiro (PDDF):

- Assistente de alfabetização

- Material de apoio didático-pedagógico

- Assistência técnica (secretarias e escolas)

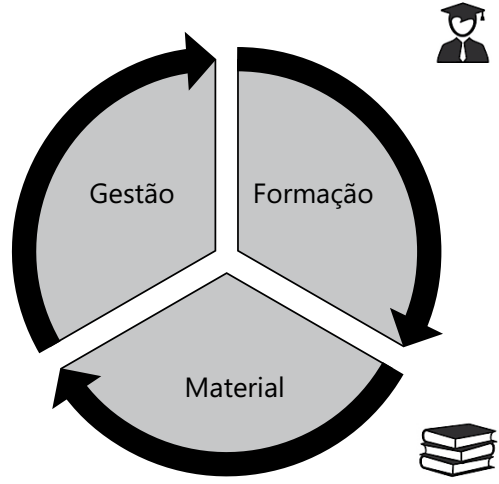

Continuada:

- Formação PNAIC aperfeiçoamento

- Mestrado profissional em alfabetização e didática aplicada Inicial: residência pedagógica

Material de alfabetização selecionado pelos estados no âmbito do PNAIC aperfeiçoado

Fonte: Brasil (2017).

Ao realizarmos uma análise da tríade proposta pelo Programa Mais Alfabetização (BRASIL, 2018), observamos que a política foi voltada para a atuação/formação do 
docente (Quadro 1). No eixo de gestão, a maior parte das políticas foi direcionada para o monitoramento das aprendizagens, tanto na sala de aula quanto também no sistema. No que se refere ao material, havia uma política de controle do que seria usado pelo professor. Por fim, a formação destinada aos docentes foi realizada com foco na prática.

Quadro 1 - Ações da tríade do Programa Mais Alfabetização

GESTÃo
Assistente de alfabetização: todo professor alfabetizador regente contará com o apoio
de um assistente de alfabetização para o desenvolvimento de atividades pedagógicas,
considerando os dados das avaliações e o plano de trabalho definido pelo professor e pela
escola com orientação da Secretaria (ação específica do PDDE).

Avaliações: diagnóstica, formativa e somativa.

Metas: estabelecimento de metas de processos e de aprendizagens para as turmas de alfabetização.

Monitoramento com devolutivas: uso dos resultados das avaliações nas formações para equipes técnicas da rede de Ensino.

Sistema com gestão de dados: inserção dos dados das avaliações, devolutiva dos resultados das avaliações para a escola e a rede (dado gerencial e detalhado) e registro dos planos de trabalho das escolas.

Acompanhamento pedagógico: protocolos e rotinas de acompanhamento pedagógico para as escolas (Secretaria com as escolas) e turmas de alfabetização (gestão escolar com professores e alunos).

Escolas vulneráveis (nível insuficiente): assistente de alfabetização com atuação ampliada e assistência técnica reforçada.

\section{MATERIAL}

Material selecionado: material de alfabetização selecionado pelos estados no âmbito do Novo Pnaic.

FORMAÇÃO

Formação continuada: Professores regentes: mestrado profissional em alfabetização e didática aplicada (priorização de professores de $1^{\circ}$ e $2^{\circ}$ anos), formação com foco na alfabetização e gestão da aprendizagem; Assistentes de alfabetização: oficinas com foco na alfabetização e gestão da aprendizagem; Gestores escolares (Diretor e Coordenador Pedagógico); Equipes técnicas das Secretarias.

Formação inicial: Residência pedagógica: direcionar os estudantes das pedagogias e licenciaturas afins para a residência no $1^{\circ}$ e no $2^{\circ}$ anos do Ensino Fundamental.

Fonte: Brasil (2018)

No entanto, na Portaria $\mathrm{n}^{\mathrm{0}}$ 142, lançada em fevereiro de 2018, e no Manual Operacional do Sistema de Orientação Pedagógica e Monitoramento, lançado em abril de 2018, não aparece a formação de professores regentes no âmbito do mestrado profissionalizante. Nesses documentos, afirma-se apenas que cabe ao governo promover as ações formativas e, aos professores regentes, participar. 
Em setembro de 2018, o MEC disponibiliza um documento para esclarecer algumas dúvidas: "Programa Mais Alfabetização - Perguntas Frequentes" (BRASIL, 2018). Nele, o governo afirma que a formação é ampla e diversificada, contemplando formação a distância, encontros e disponibilização de materiais. O documento discorre de forma detalhada sobre o curso "Desenvolvimento Profissional", que é oferecido para todos os agentes escolares, com 40h de carga horária. Sobre o mestrado, o MEC afirma que a portaria não prevê tal ação e que a política de formação de professores com base no programa ainda está sendo delineada. Ao observar o foco do Programa Mais Alfabetização, podemos perceber que, juntamente com a ANA, o governo ocupa o papel de agente que controla e monitora as ações. De acordo com Fernandes (2008, p. 106), o controle ocorre no sentido de, "através de exames estandardizados e por si controlados, assegurarem que conteúdos semelhantes sejam lecionados nas escolas de acordo com o previsto no currículo nacional"; já o monitoramento "consiste na utilização dos resultados dos exames para pedir contas às escolas e aos professores". Essa política de controle e monitoramento acaba por tentar retirar do professor sua contribuição intelectual, que o caracteriza como profissional, colocando-o, dessa forma, no papel de técnico. Tal movimento, assim como afirma Tardif (2013), contribui para o retardo do reconhecimento do Ensino como profissão e não mais como ofício.

Dentre a tríade de ação do Programa e as ações que competem aos diferentes agentes, realizaremos uma análise no que se refere à formação continuada do professor e à gestão da avaliação.

\subsection{Formação continuada}

A partir da análise do Programa Mais Alfabetização, observa-se também, para além de outras diretrizes, que programas de formação continuada de professores estão sendo pensados a partir dos resultados de avaliação externa da aprendizagem dos alunos. Segundo Alavarse et al. (2017), a partir da ampliação de políticas de avaliações externas, houve a construção de novos debates sobre a formação docente. Gatti (2008) considera que a formação de professores entrou em pauta mundial devido a dois movimentos: por um lado, pelas pressões do mundo do trabalho; por outro, devido aos precários desempenhos escolares. Com isso, políticas públicas passam a ser desenvolvidas na direção de reformas curriculares e de mudanças na formação de professores.

Atualmente, pode-se destacar que a formação de professores, pensada a partir da avaliação externa, apresenta duas vertentes. A $1^{a}$ consiste na ideia de que o professor deve ser o principal usuário do resultado da avaliação externa, no 
sentido de articulá-lo com o desenvolvimento do seu trabalho pedagógico na escola. Para que isso ocorra, é "primordial que os professores compreendam os meandros das avaliações externas e, principalmente, as alternativas de seus usos como recurso pedagógico na sala de aula" (ALAVARSE et al., 2017, p. 1.357). Isso levaria a uma formação direcionada ao conhecimento dos conceitos e dos métodos, além dos usos dos resultados das avaliações externas, bem como à sua relação com o trabalho pedagógico em sala de aula. $\mathrm{O}$ objetivo seria capacitar o maior número de profissionais da rede de Ensino na leitura e na interpretação dos resultados do sistema e dos fatores contextuais. Além disso, é fundamental também a capacitação para a elaboração de itens, que tem como objetivo intensificar as ações pedagógicas com base na vivência de elaboração, de análise e de construção de itens de avaliação externa.

A segunda vertente busca atrelar o resultado do rendimento dos alunos a tópicos de formação de professores, ou seja, realizar ações de formação contínua de professores com base nos resultados da avaliação. A avaliação externa passa a determinar o que deve ser desenvolvido na formação continuada dos professores. De acordo com Prada (2001, p. 98), nesse caminho se evidencia a "eficácia e eficiência do trabalhador da Educação" no lugar do "desenvolvimento do ser humano profissional e docente inserido na cultura local (escola), da região e do país onde trabalha".

Seguindo essa vertente, o Programa Mais Alfabetização iniciou-se com a ideia de realizar uma formação, para o professor regente, no nível de mestrado profissional em alfabetização e em didática aplicada (priorização de professores de $1^{\circ} \mathrm{e}$ $2^{\circ}$ anos), formação com foco na alfabetização e na gestão da aprendizagem. No entanto, essa ideia não foi concretizada, porque, ao ser lançado, o programa não deixa claro como será essa formação. Apenas informa, posteriormente, a possibilidade de capacitação em um curso a distância de $40 \mathrm{~h}$, considerada uma formação para o desenvolvimento profissional. Nesse sentido, observa-se um direcionamento de políticas de formação de professores voltado para cursos aligeirados, que apresentam como objetivo apenas a reformulação da prática, excluindo reflexão crítica e estudos teóricos do trabalho docente e anulando a possibilidade de formação e de desenvolvimento de trabalho qualificados. Por conseguinte, o programa visa atrelar o resultado do rendimento do aluno na ANA à formação de professores (MORAES, 2019). De acordo com Bauer (2012), é importante refletir sobre esse discurso, que relaciona, de forma direta, a formação continuada do professor como melhoria da aprendizagem dos alunos, tendo em vista que tal perspectiva pressupõe que o problema da qualidade do Ensino se resumiria à formação e ao desempenho docente. 
Para o entendimento completo do desempenho do aluno, é imprescindível que haja uma análise ampla dos diferentes fatores que interferem no desempenho. Soares (2007) apresenta um modelo conceitual no qual destaca os diferentes fatores que influenciam o processo de aprendizagem (Gráfico 2).

Gráfico 2 - Fatores que influenciam o processo de aprendizagem

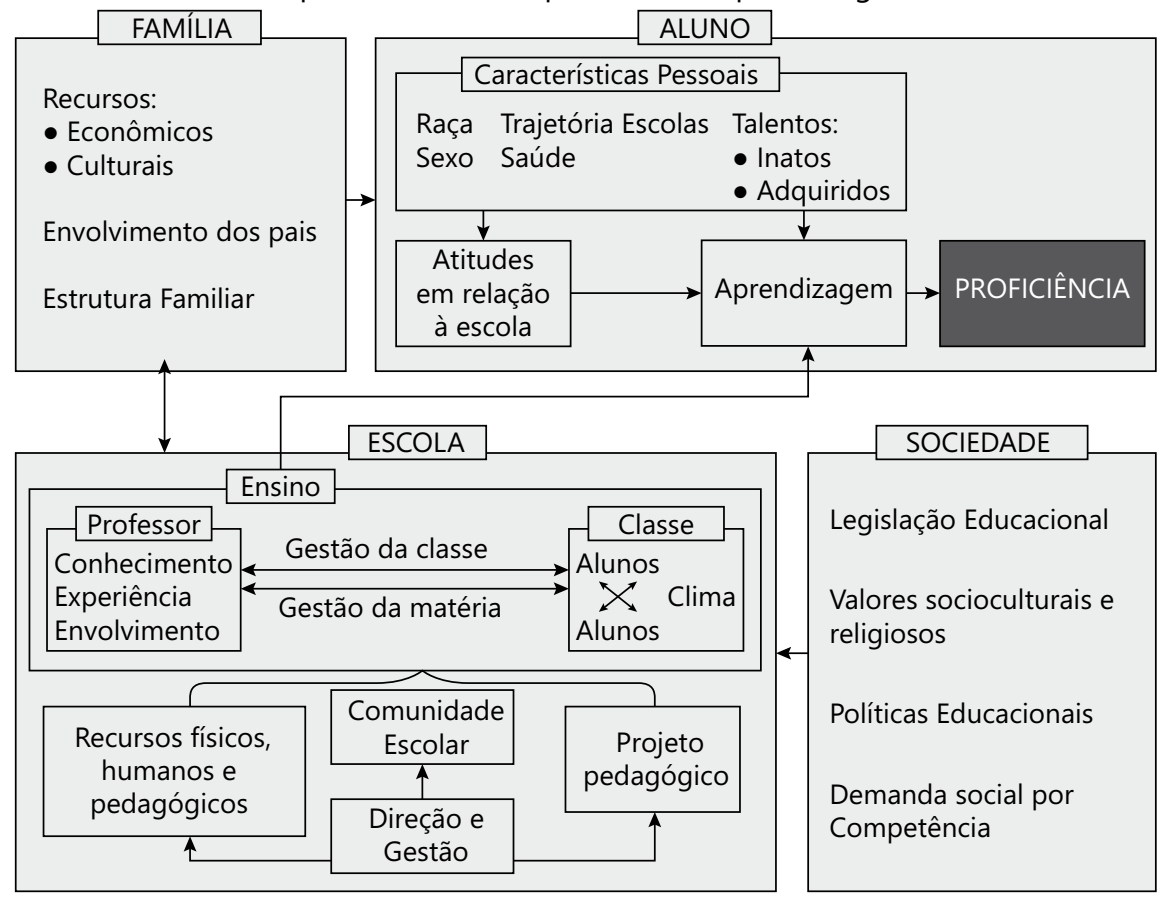

Fonte: Soares (2007)

Em contrapartida, Brunner (2003), com base em estudos, afirma que o insumo escolar que mais influencia positivamente no rendimento do aluno é o professor conhecer a matéria. $\mathrm{O}$ autor afirma que a qualidade do Ensino estaria determinada, em grande parte, pela atuação docente. Darling-Hammond (2000) aponta que os investimentos em políticas de qualidade dos professores podem estar relacionados a melhorias no desempenho dos alunos.

A partir da análise do Programa Mais Alfabetização, observa-se que, tanto no que se refere à atuação quanto à formação dos docentes, é forte a ideia de que se deve investir no professor para melhorar o desempenho discente, assim como em 
políticas públicas que tomam como base o resultado das avaliações de desempenho dos alunos. Isso mostra como o Estado vem acentuando a expectativa de que os resultados da avaliação externa venham a subsidiar as iniciativas de formação continuada dos professores com vistas ao aprimoramento das práticas pedagógicas (SOUSA; OLIVEIRA, 2010). Entretanto, esse fato ainda não encontra evidências consistentes na literatura, necessitando de mais estudos (SCHNEIDER et al., 2020).

\subsection{Gestão: avaliações}

A partir dos dados gerados pelas duas primeiras avaliações do ANA, formulou-se o Programa Mais Alfabetização, que, dentre as suas ações, visa realizar avaliações diagnósticas, formativas e somativas, como forma de monitoramento.

Parte do sistema de monitoramento ficou sob responsabilidade do Centro de Políticas Públicas e Avaliação da Educação $(\mathrm{CAEd})^{2}$, o qual se encarregou de elaborar "uma proposta de avaliação constituída por testes e relatórios que visam balizar não apenas as ações pedagógicas desenvolvidas pela escola, como também a formação dos assistentes e o acompanhamento da execução do Programa, com base em indicadores confiáveis" (BRASIL, 2018, p. 15). Acerca dessa ação, podemos analisar que a avaliação dos alunos ao longo do ano letivo será realizada também por um agente externo, tendo em vista que as avaliações e os relatórios de desenvolvimento serão feitos pelo CAEd, a pedido do MEC, pois cabe a ele

III - criar e implementar mecanismos de monitoramento a serem incorporados à rotina das secretarias e gestão escolar, por meio de avaliações diagnósticas e formativas; e VII - dar suporte à rotina de acompanhamento sistemático, pelas redes de Ensino e gestão escolar, da evolução da aprendizagem dos estudantes regularmente matriculados no $1^{\circ}$ ano e no $2^{\circ}$ ano do Ensino Fundamental.

Aos estados, Distrito Federal e municípios, cabe

IX - gerenciar e monitorar, na sua rede de Ensino, as ações do Programa, com vistas ao cumprimento das finalidades estabelecidas pelo Programa; e XII - garantir, no período definido pelo MEC, a aplicação das avaliações diagnósticas e formativas a todos os estudantes regularmente matriculados no $1^{\circ}$ ano e no $2^{\circ}$ ano do Ensino Fundamental e a inserção dos seus resultados no sistema do Programa.

O CAEd é vinculado à Universidade Federal de Juiz de Fora (UFJF) e tem por finalidade elaborar e desenvolver programas, em níveis estadual e municipal, destinados a mensurar o rendimento de estudantes das escolas públicas. 
E, por fim, às comunidades escolares, restringe-se o papel de aplicadores, tendo em vista que são responsáveis por

$\mathrm{V}$ - aplicar avaliações diagnósticas e formativas, com vistas a possibilitar o monitoramento e a avaliação periódica da execução e dos resultados do Programa; e VI - aplicar, no período definido pelo MEC, as avaliações diagnósticas e formativas a todos os estudantes regularmente matriculados no $1^{\circ}$ ano e no $2^{\circ}$ ano do Ensino Fundamental e inserir seus resultados no sistema de monitoramento do Programa (BRASIL, 2018).

Não fará parte da nossa análise, mas cabe ressaltar que as metas também são de suma importância nessa cultura avaliativa, pois na medida em que se tem por objetivo o estabelecimento de metas de processos e aprendizagens para as turmas de alfabetização, tende-se a realizar uma padronização para a obtenção da meta estabelecida e monitorada por diferentes avaliações periodicamente.

A partir dessa análise, entendemos que a política voltada para a alfabetização a partir dos resultados da ANA, principalmente no que se refere às avaliações, é altamente regulatória, assim como afirma Esteban (2012) sobre a política de avaliação da alfabetização. Entende-se que a política é regulatória na medida em que, por meio de mecanismos de controle, reduz a autonomia do professor, principalmente no tocante ao cotidiano da prática pedagógica, levando-o a ocupar um espaço mais técnico do que profissional.

\section{Conclusões}

Apesar da característica complexa e multifacetada da alfabetização, pode-se notar que, nas políticas públicas, assim como afirma Mortatti (2010), há uma atenção a alguns aspectos específicos da alfabetização, reduzindo-a a aspectos neutros e meramente técnicos. Esse caráter redutor é preocupante, principalmente em políticas públicas de Educação que visam regular o trabalho docente.

Como analisado, o Programa Mais Alfabetização, como resposta aos resultados insatisfatórios da ANA, propõe uma política do governo de maior controle e monitoramento, o que acentua a percepção de que existe uma relação direta entre a capacitação do professor e a melhoria do desempenho dos alunos. São desenvolvidas, assim, ações que, por vezes, podem reduzir a autonomia do docente, que é considerado um técnico, não obtendo um espaço de reflexão crítica e desenvolvimento profissional. Em destaque, salientamos as avaliações 
aplicadas ao longo do ano letivo por um avaliador externo, o que pode ter gerado um impacto maior no cotidiano da prática pedagógica do docente, tendo em vista que considera que tais avaliações apresentam "indicadores confiáveis", retirando do professor sua capacidade de avaliar.

Como afirma Bauer (2012), não há a intenção de se afirmar que os resultados dos testes em larga escala da aprendizagem dos alunos não devem ser utilizados como dados para a tomada de decisões de políticas públicas. No entanto, deve-se "chamar a atenção para o fato de que esse uso não pode ser realizado de forma simplista, sem que a natureza da informação por eles produzida seja considerada" (BAUER, 2012, p. 74).

O programa foi encerrado pelo MEC em dezembro de 2019 e o governo não apresentou nenhum relatório ou estudo sobre o seu desenvolvimento ou impactos de suas ações. 


\title{
Public policies in literacy: a dialogue with the national literacy evaluation test and the Programa Mais Alfabetização (Plus Literacy Program)
}

\begin{abstract}
Recurrent results of failure of literacy in Brazil and public policies associated to it are objects of discussion in this paper, which analyses links between external evaluation resources, public policies, and everyday pedagogical practices. Analysis is made upon the official program named Programa Mais Alfabetização ("Plus Literacy Program”), implemented in 2018 as an answer to low levels of skills attested through the results of Avaliação Nacional de Alfabetização (National Literacy Evaluation Test). Based on specific literature, this paper presents a theoretical survey on public policies dedicated to literacy in Brazil and on the external evaluation of student learning. Observed documentation shows, in synthesis, that the program, specifically designed as an answer to external evaluation results, tends to focus on teacher's education and practical activities, on controlling and on monitoring of pedagogical practices.
\end{abstract}

Keywords: Literacy. External Evaluation. Public Policies.

\section{Políticas públicas en alfabetización: un diálogo con la evaluación nacional de alfabetización y el Programa Mais Alfabetização (Programa Más Alfabetización)}

\section{Resumen}

El resultado histórico del fracaso de la alfabetización en el contexto brasileño y las políticas públicas desarrolladas a partir de este escenario son objeto de discusión en este texto, que explora la relación entre la evaluación externa del aprendizaje de los estudiantes, las políticas públicas y las prácticas pedagógicas cotidianas. Para ello, se decidió realizar un análisis del documento rector del Programa Mais Alfabetização, implementado en 2018, en respuesta a los bajos niveles de desempeño de los estudiantes en la Evaluación Nacional de Alfabetización. A partir de los aportes de la literatura, se presenta una discusión teórica sobre las políticas públicas de alfabetización y la evaluación externa del aprendizaje de los estudiantes. Lo que observamos es que, en resumen, el programa desarrollado en respuesta a los resultados de la evaluación externa tiende a enfocarse en la formación y el desempeño docente, en el control y seguimiento de las prácticas pedagógicas.

Palabras clave: Alfabetización. Evaluación Externa. Políticas Públicas. 


\section{Referências}

ALAVARSE, O. M.; MACHADO, C.; ARCAS, P. H. Avaliação externa e qualidade da educação: formação docente em questão. Revista Diálogo Educacional, Curitiba, v. 17, n. 54, p. 1353-1375, jul./set. 2017. https://doi.org/10.7213/1981-416X.17.054.AO04

ALFERES, M. A.; MAINARDES, J. O pacto nacional pela alfabetização na idade certa em ação: revisão de literatura. Ensaio: Avaliação e Políticas Públicas em Educação, Rio de Janeiro, v. 27, n. 102, p. 47-68, jan./mar. 2019. https://doi.org/10.1590/S0104-40362018002601262

BAUER, A. É possível relacional avaliação discente e formação de professores? A experiência de São Paulo. Educação em Revista, Belo Horizonte, v. 28, n. 2, p. 61-82, jun. 2012. https://doi.org/10.1590/S0102-46982012000200004

BRASIL. Ministério da Educação. Avaliação nacional da alfabetização ANA: documento básico. Brasília, 2013. Disponível em: http://docplayer.com. br/1782802-Avaliacao-nacional-da-alfabetizacao-ana-documento-basico.html. Acesso em: 20 jul. 2018.

BRASIL. Ministério da Educação. Caderno de apresentação. Brasília, DF, 2015.

BRASIL. Ministério da Educação. Conferência nacional de educação (Conae) 2010: construindo o sistema nacional articulado de educação: o plano nacional de educação, diretrizes e estratégia de ação: documento final. Brasília, DF, 2010. Disponível em: portal.mec.go.br/arquivos/pdf/conae/documento_ referencia.pde. Acesso em: 20 jul. 2018.

BRASIL. Ministério da Educação. Portaria nº 867, de 4 de julho de 2012. Institui o pacto nacional pela alfabetização na idade certa e as ações do pacto e define suas diretrizes gerais. Diário Oficial da União, 5 jul. 2012.

BRASIL. Ministério da Educação. Política nacional de alfabetização: outubro de 2017. Brasília, DF, 2017. Disponível em: http://portal.mec.gov.br/docman/ outubro-2017-pdf/75191-mais-alfabetizacao-apresentacao-251017-pdf/file. Acesso em: 20 jul. 2018.

BRASIL. Ministério da Educação. Programa mais alfabetização: manual operacional do sistema de orientação pedagógica e monitoramento. Brasília, DF, 2018. Disponível em: http://portal.mec.gov.br/docman/abril-2018pdf/85691-manual-operacional-pmalfa-final/file. Acesso em: 5 ago. 2018. 
BRASIL. Ministério da Educação. Provinha Brasil: passo a passo. Brasília, 2008.

BRUNNER, J. J. Límites de la lectura periodística de resultados educacionales. In: IAIES, G. et al. Evaluar las evaluaciones: una mirada política acerca de las evaluaciones de la calidad educativa. Buenos Aires: United Nations Educational, Scientific and Cultural Organization, 2003. p. 67-84

CASASSUS, J. A escola e a desigualdade. Cadernos de Pesquisa, São Paulo, n. 119, p. 205-206, jul. 2013.

CLÍMACO, M. C. Avaliação de sistemas em educação. Lisboa: Universidade Aberta, 2005.

DARLING-HAMMOND, L. Teacher quality and student achievement. Education Policy Analysis Archives, Tempe, v. 8, n. 1, p. 1-44, jan. 2000. https://doi.org/10.14507/epaa.v8n1.2000

ESQUINSANI, R. S. S. O pacto nacional pela alfabetização na idade certa e a responsabilização (accountability) do professor alfabetizador. Revista Ibero-Americana de Estudos em Educação, Araraquara, v. 11, n. esp. 4, p. 2465-2482, 2016. https://doi.org/10.21723/riaee.v11.n.esp4.9203

ESTEBAN, M. T. Considerações sobre a política de avaliação da alfabetização: pensando a partir do cotidiano escolar. Revista Brasileira de Educação, Rio de Janeiro, v. 17, n. 51, p. 573-743, set./dez. 2012. https://doi.org/10.1590/S1413-24782012000300005

FERNANDES, D. Avaliação das aprendizagens: desafios às teorias, práticas e políticas. Lisboa: Texto, 2008.

FERREIRA, P. F.; FONSECA, M. S. A cultura da performatividade na organização do trabalho pedagógico: a formação matemática nos cadernos do pacto nacional pela alfabetização na idade certa (Pnaic). Ensaio: Avaliação e Políticas Públicas em Educação, Rio de Janeiro, v. 25, n. 97, p. 809-830, dez. 2017. https://doi.org/10.1590/s0104-40362017002500901

GATTI, B. A. Análise das políticas públicas para formação continuada no Brasil, na última década. Revista Brasileira de Educação, Rio de Janeiro, v. 13, n. 37, p. 57-70, jan./abr. 2008. https://doi.org/10.1590/S1413-24782008000100006

KELLAGHAN, T.; MADAUS, G. External (public) examinations. In: KELLAGHAN, T.; STUFFLEBEAM, D. L. (eds.). International handbook of educational evaluation. Dordrecht: Kluwer Academic, 2003. p. 577-600. 
MORAES, A. C. A. Análise do programa mais alfabetização: precarização na formação e trabalho docente. Revista do Instituto de Políticas Públicas de Marília, Marília, v. 5, n. 1, p. 109-126, jan./jul. 2019. https://doi.org/10.36311/2447-780X.2019.v5.n1.10.p109

MORAIS, A. G.; LEAL, T. F.; ALBUQUERQUE, E. B. C. "Provinha Brasil": monitoramento da aprendizagem e formulação de políticas educacionais. Revista Brasileira de Política e Administração da Educação, Goiânia, v. 25, n. 2, p. 301-320, maio/ago. 2009. https://doi.org/10.21573/vol25n22009.19499

MORTATTI, M. R. L. Alfabetização no Brasil: conjecturas sobre as relações entre políticas públicas e seus sujeitos privados. Revista Brasileira de Educação, Rio de Janeiro, v. 15, n. 44, p. 329-341, maio/ago. 2010. https://doi.org/10.1590/S1413-24782010000200009

PRADA, L. E. A. Formação continuada de professores: experiências em alguns países. Educação Temática Digital, Campinas, v. 2, n. 3, p. 97-116, jun. 2001. https://doi.org/10.20396/etd.v2i3.584

SCHNEIDER, N. M. A. W. A.; GROSCH, M. S.; DRESCH, J. F. Reflexões sobre o impacto da política pública do PNAIC na formação continuada das professoras alfabetizadoras de Lages-SC. Ensaio: Avaliação e Políticas Públicas em Educação, Rio de Janeiro, v. 18, n. 107, p. 435-456, abr./jun. 2020. https://doi.org/10.1590/S0104-40362019002701632

SHIMAZAKI, E. M.; MENEGASSI, R. J. O formador de professores de língua portuguesa do Pnaic e as alterações em suas práticas profissionais. Práxis Educativa, Ponta Grossa, v. 11, n. 1, p. 199-213, jan./abr. 2016. https://doi.org/10.5212/PraxEduc.v.11i1.0009

SOARES, J. F. Melhoria do desempenho cognitivo dos alunos do ensino fundamental. Cadernos de Pesquisa, São Paulo, v. 37, n. 130, p. 135-160, jan./abr. 2007. https://doi.org/10.1590/S0100-15742007000100007

SOUSA, S. Z.; OLIVEIRA, R. P. Sistemas estaduais de avaliação: uso dos resultados, implicações e tendências. Cadernos de Pesquisa, São Paulo, v. 40, n. 141, p. 793-822, set./dez. 2010. https://doi.org/10.1590/S0100-15742010000300007

SPALA, F. T. Da palavra falada à palavra da escola: um estudo sobre as orientações didáticas à alfabetização na cidade do Rio de Janeiro. Tese (Doutorado em Educação) - Universidade do Estado do Rio de Janeiro, Rio de Janeiro, RJ, 2015. 
TARDIF, M. A profissionalização do ensino passados trinta anos: dois passos para a frente, três para trás. Educação \& Sociedade, Campinas, v. 34, n. 123, p. 551-571, abr./jun. 2013.

\section{Informações sobre os autores}

Helen Vieira de Oliveira: Doutora em Educação pelo Programa de Pós-Graduação em Educação do Instituto de Educação da Universidade de Lisboa. Contato: helenvoliveira@gmail.com

(iD) https://orcid.org/0000-0003-3466-3905

Dina Maria Vieira Pinho: Doutora em Educação pela Universidade Estadual do Rio de Janeiro. Contato: dmvpinho@gmail.com

(iD) http://orcid.org/0000-0002-0943-9349

Luiz Antonio Gomes Senna: Doutor em Linguística Aplicada pela Universidade Católica do Rio de Janeiro. Professor Titular do Programa de Pós-Graduação em Educação da Universidade Estadual do Rio de Janeiro. Contato: senna@senna.pro.br

(iD) https://orcid.org/0000-0002-1086-8829 